\title{
POST-CAUSTIC BURN SEVERE MICROSTOMIA OF AN ADULT, CORRECTED BY RELEASE OF SCAR AND SPLIT-THICKNESS SKIN GRAFT- A TECHNIQUE
}

\section{Radharaman Panda ${ }^{1}$}

${ }^{1}$ Former Assistant Professor, Department of General Surgery, LSLAM Government Medical College, Raigarh.

HOW TO CITE THIS ARTICLE: Panda R. Post-caustic burn severe microstomia of an adult, corrected by release of scar and splitthickness skin graft- A technique. J. Evolution Med. Dent. Sci. 2017;6(77):5516-5518, DOI: 10.14260/Jemds/2017/1198

\section{PRESENTATION OF CASE}

A 27-year-old male patient, a farmer, came from a remote village with complaints of inability to open the mouth and difficulty in taking food past 3 months. He gave a history of accidental intake of washing soda at night after taking dinner which he spitted out immediately due to bad taste. Immediately he washed his mouth with plain water. He consulted the local doctor, but gradually developed restriction of opening of mouth and inability to take food. He had no difficulty in swallowing food, no history of vomiting and reflux of food. On examination, mouth opening was 'One finger' breadth, mouth was constricted, lower lip gingivolabial sulcus was obliterated due to dense scarring. Lateral half of both lips was fused. On trying to open the mouth, there was muscle bulge surrounding the mouth (Fig. 1). Patient was unable to speak properly and unable to maintain the oral hygiene properly.

\section{DIFFERENTIAL DIAGNOSES}

Differential diagnoses of microstomia are temporomandibular joint ankylosis, post maxillofacial trauma and submucosal fibrosis of oral cavity.

\section{CLINICAL DIAGNOSIS}

Routine investigation of blood, LFT, RFT and chest X-Ray was normal. Patient was diagnosed as having Microstomia.

\section{Management/Operative Technique Marking}

Marking was done by methylene blue dye. A line was drawn vertically from pupil of eye ball downwards on both sides and another horizontal line was drawn parallel to upper border of the lower lip. Angle of mouth was formed on both sides of mouth where the vertical and horizontal lines meet (Fig. 1). Diluted injection Adrenaline (1:200000) was infiltrated subcutaneously on the operated site of both upper and lower lips.

\section{Release of Scar \& Graft Placement}

Microstomia with fibrous adhesion of both lips was released by giving incisions starting from medial side of lip to the point where the angle of mouth is to be formed as per marking given earlier. Obliterated lower gingivolabial sulcus was released by giving incision close to inner side of lower lip.

Financial or Other, Competing Interest: None.

Submission 10-07-2017, Peer Review 13-09-2017,

Acceptance 19-09-2017, Published 25-09-2017.

Corresponding Author:

Dr. Radharaman Panda,

Sambalpur-768004,

Odisha.

E-mail: drradharaman@yahoo.co.in

DOI: $10.14260 /$ jemds $/ 2017 / 1198$

\section{(c) (1) $(9)$}

In upper lip, the raw area was repaired primarily by adjacent mucosal mobilisation by delayed absorbable suture (polyglactin). After release of scar, the raw area was formed at the lower lip, lower gingivolabial sulcus and both angles of mouth. Secondary defect (raw area after release) length and width was measured. Medium thickness skin graft was taken from lateral side of right thigh as per measurement of secondary defect. Single sheet skin graft was cleaned by normal saline and placed entirely on lower lip covering the gingivolabial sulcus and both angles of mouth. Graft was stitched to the outer border of lower lip with 5-0 silk suture and the suture was cut at $5-6 \mathrm{~cm}$ distance from the knot. Similarly, 3-4 elongated sutures were given (suture-1).

\section{Graft Immobilisation}

From the angle of mouth, graft was held by two rounded boluses of tulle (structurally they comprise a gauze cloth impregnated with petroleum jelly) placed on both inner and outer side of angle of mouth. Both boluses were pierced by a needle with suture through and through, starting from outer side to inside of angle of mouth and returning back to outside of angle of mouth. Suture knot was given on the outer side of angle of mouth over the bolus (Fig. 2). Graft was placed on lower gingivolabial sulcus, and a thick elongated rolled gauze soaked with petroleum jelly (tulle) placed on skin graft as per contour of sulcus (Fig. 2a) and another elongated and thick bolus tulle kept on the outer side of lower lip just below it. Both sides of thick bolus was retained by silk suture passing from outer side of lower lip to inner side of lower lip piercing the needle through both boluses of tulle and back to outer side of lower lip (Fig. 2b). The suture was then tied and thread was cut at 5- $6 \mathrm{~cm}$ distance from the knot (suture-2). Another thin elongated tulle bolus was kept on remaining area of lower lip and elongated thread of suture- 1 was tied over the bolus with elongated thread of suture- 2 just below the lower lip (tie over bolus dressing). About 4-5 sutures were given for lower lip (Fig. 2b). Dry gauze was kept over the lower lip with little pressure. Skin adhesive tape covering the lower lip and both sides of cheek was applied. Postoperatively, the patient was kept nil orally for 6 hours. After that patient was allowed to take normal food and advised for frequent mouth wash with plain water after each meal. On $10^{\text {th }}$ post-operative day, dressing was opened. Graft was taken up $100 \%$. All stitches were removed. Mouth opening was 3 fingers vertically and normal. Patient was advised to do frequent mouth opening and closing exercise. Patient was called for followup in 1 month, 2 months, 3 months, 6 months, 1 year, 18 months. On 18 months of followup, patients mouth opening and function of lips was normal (Fig. 3). From a cosmetic point of view, slightly dark colour of lip on grafted area was seen. Patient was satisfied with this outcome. 


\section{PATHOLOGICAL DISCUSSION}

Caustic substances are those that can burn, corrode or destroy the living tissue. Broadly, it is classified into acids and alkalis. Severity and extent of injury is less in accidental ingestion than deliberate ingestion. Alkali ingestion is more common than acid ingestion because of no immediate symptoms. Caustic substances cause tissue destruction through liquefaction or coagulation reactions and the intensity of destruction depends on the type, concentration, time of contact and amount of the substance ingested.[1]Alkali ingestion is much more devastating and almost always Leads to significant destruction of tissue, resulting in long-term dysfunction. Alkali ingestion causes liquefactive injury ${ }^{[2]}$ and deep penetration of tissue. After liquefactive necrosis, ulcer forms and gradually scarring of tissue occurs followed by scar contraction. In this case, both lower and upper lips and Gingivolabial sulcus got ulcerated after accidental ingestion of alkali leading to fusion of both lips by fibrous adhesion. Later on, severe scar formation and contraction led to constriction of Vestibule of mouth leading to Microstomia (Fish mouth opening).

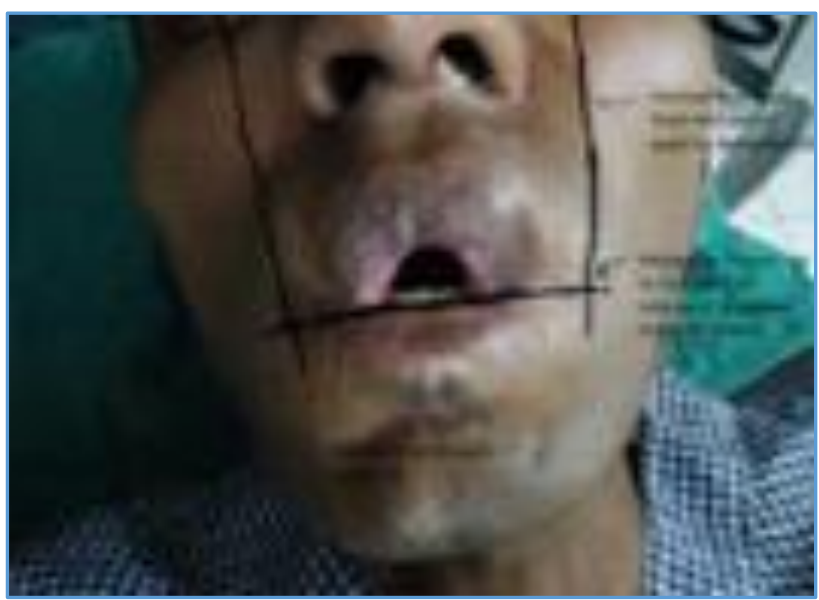

Figure 1. Microstomia of an Adult Male, Marking for Correction

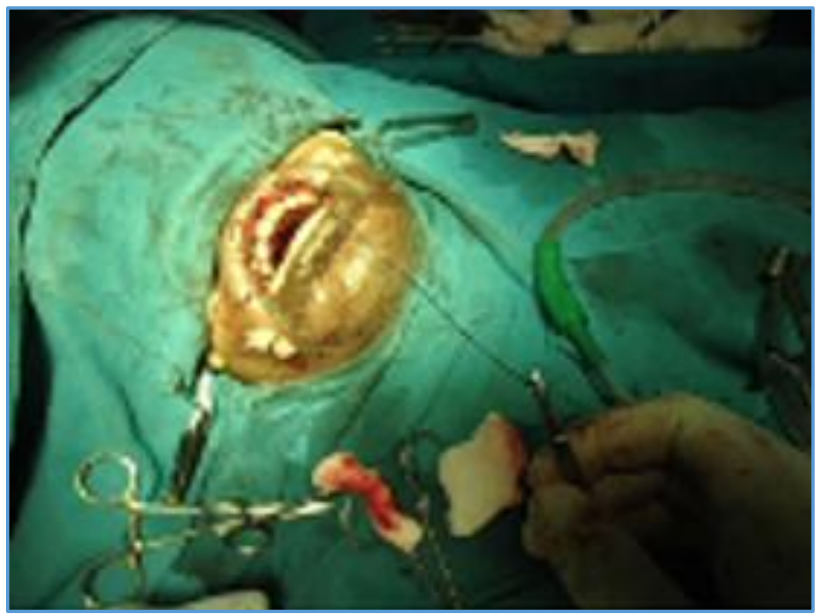

Figure 2. Tieover bolus dressing with suture knot at angle of mouth and elongated suture at lower lip

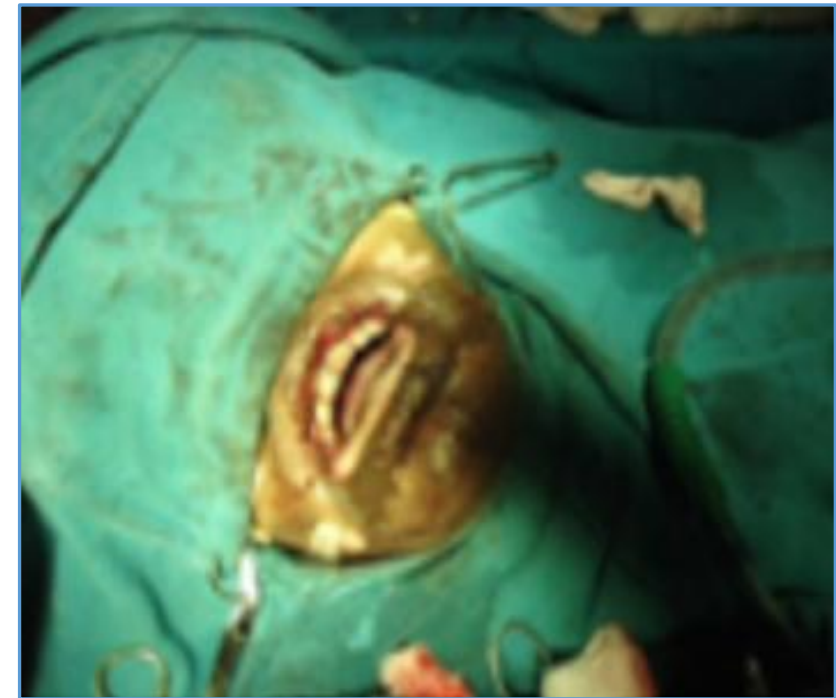

Figure 2a. Bolus of tulle placed on skin graft on gingivolabial sulcus of lower lip

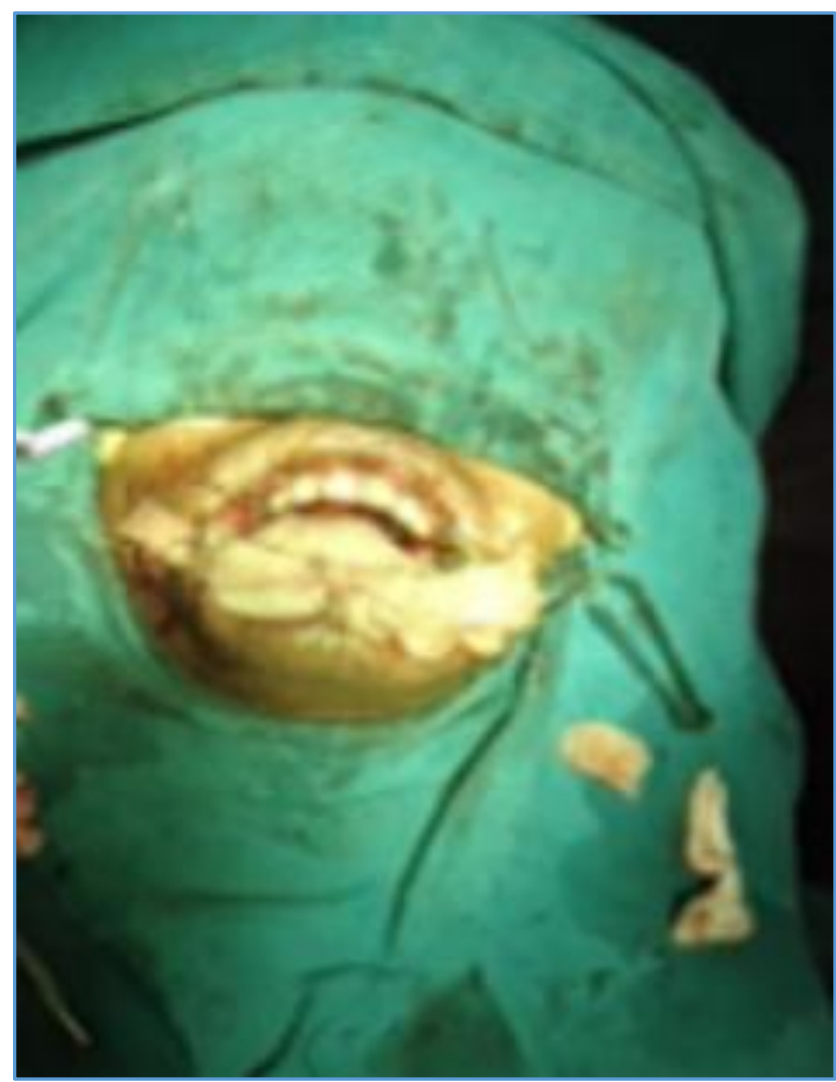

Figure $2 b$. Tie over bolus dressing with suture knot on outer side of lower lip 


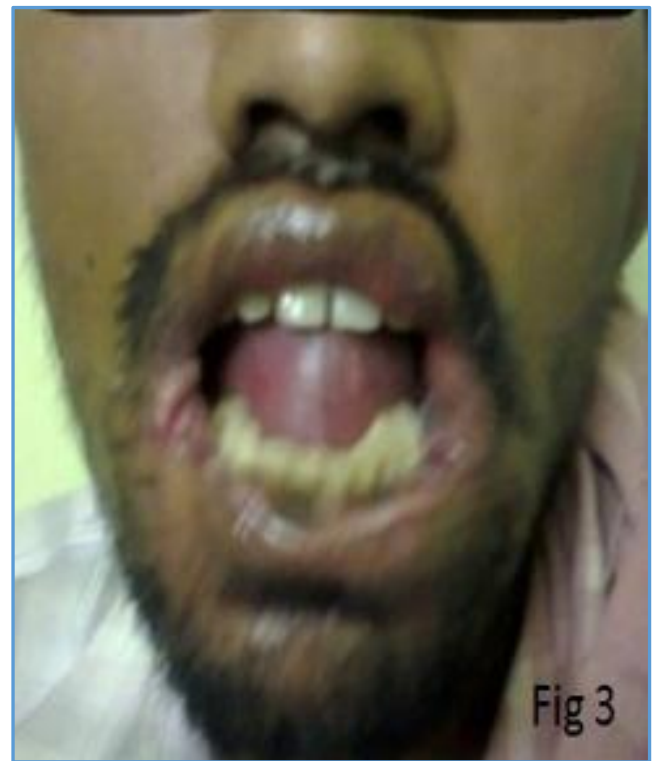

Figure 3. Postoperative result of mocrostomia

\section{DISCUSSION OF MANAGEMENT}

Several techniques have been described for the reconstruction of the labial commissure for correction of microstomia such as excision of scar at angle of mouth and defect closure with mobilisation of Buccal mucosa, Y-V plasty and Z-plasty of angle of mouth. Perioral contractures after burn (Microstomia) is a consequence of facial burns treated surgically earlier by release of scar and Trapezoid-shaped single buccal mucosal advancement flap ${ }^{[3]}$ and reconstruction of oral commissure by an oral lower lip mucosal rotation flap, modification based on Fairbank's technique.[4]

These abovementioned methods are applicable for correction of mild-to-moderate post-burn perioral contracture causing microstomia. In severe microstomia with dense fibrous fusion of both lips, obliterated gingivolabial sulcus and deformed angle of mouth, due to extensive scarring, an oral mucosal flap is not enough to correct the deformity adequately. So skin grafting is ideal.

Isolated Caustic injury of lower and upper lip of mouth causing severe microstomia is very rare and unusual. The aims of corrective surgery of post-burn deformity should be to preserve, restore, and maintain function and appearance so the patient can recover to be healthy both physically and mentally. Corrective surgery is delayed until the scar tissue has fully matured, except in presence of severe contractures.
(Severe microstomia, growth disturbance, unstable scars \& corneal exposure with Ectropion.) ${ }^{[5]}$

The Technique Adopted here for Surgical Correction of Microstomia -

1. Release of scar without scar excision.

2. The point to which the releasing incision is given to form the angle of mouth. By observation it was found that the angle of mouth is situated at a point where the imaginary vertical line intersects with the horizontal line parallel to lower lip. This observation is found in all normal adult faces.

3. Skin graft placed on gingivolabial sulcus and angle of lower lip, technique applied to hold the graft for proper graft take-up and prevent displacement of graft. Patient will take his food with movement of lip without any harm to grafted area. In this technique, there was no graft rejection, graft take-up was excellent, and patient had less post-operative morbidity without any disturbance of eating habit of patient. On post-operative followup, negligible secondary contracture of graft was seen with well-formed angle of mouth and lower Gingivolabial sulcus, normal mouth opening (3 fingers), acceptable cosmetic and normal oral vestibular opening. No donor area defect was seen.

\section{FINAL DIAGNOSIS}

Post-caustic burn severe microstomia.

\section{REFERENCES}

[1] Mamede RC, de Mello Filho FV. Ingestion of caustic substances and its complications. Sao Paulo Med J 2001;119(1):10-5.

[2] Greenwood JE, Tan JL, Ming JC, et al. Alkalis and skin. J BurnCare Res 2016;37(2):135-41.

[3] Grishkevich VM. Post-burn microstomia: anatomy and elimination with trapeze-flap plasty. Burns 2011;37(3):484-9.

[4] Spanholtz TA, Theodorou P, Phan V, et al. Reconstruction of the oral commissure in microstomia patients with deep dermal facial burns: a modified technique. Handchir Mikrochir Plast Chir 2007;39(5):350-5.

[5] Costagliola M. General principles of burn reconstruction. Ann Chir Plast Esthet 2011;56(5):354-7. 